\title{
Efectividad de intervenciones en la comunicación en niños con TEA. Una revisión teórica
}

\author{
Andrea Vanacloig López. Universitat de Valencia \\ Diana Marín Suelves. Universitat de Valencia (D) 0000-0002-5346-8665
}

María Martínez Antón. Universitat de Valencia

Recepción: 12.02.2020 | Aceptado: 30.06.2020

Correspondencia a través de ORCID: Diana Marín Suelves

iD 0000-0002-5346-8665

Citar: Vanacloig, A., Marín, D. y Martínez, A. (2020). Efectividad de las intervenciones en la comunicación de niños con TEA. REIDOCREA, 9, 121-137.

Resumen: El Trastorno del Espectro Autista conlleva importantes dificultades en la competencia comunicativa y social. En estas líneas se presentan los resultados de una revisión bibliográfica centrada en el análisis de la efectividad de intervenciones llevadas a cabo en los últimos años, cuyo objetivo fue la mejora de la competencia comunicativa en alumnado con trastorno del espectro autista (TEA). Tras la búsqueda en diferentes bases de datos se seleccionaron un total de 24 artículos. Se observa una mejora de las habilidades comunicativas de los participantes en todas las intervenciones examinadas y se plantean líneas futuras de investigación a partir de las bondades y limitaciones encontradas, así como pautas para el diseño de intervenciones basadas en la evidencia científica.

Palabra clave: TEA

\section{Effectiveness of communication interventions in children with ASD. A theoretical review}

Abstract: Autism Spectrum Disorder entails significant difficulties in communicative and social competence. These lines present the results of a bibliographic review focused on the analysis of the effectiveness of interventions carried out in recent years, whose objective was the improvement of communicative competence in students with autism spectrum disorder (ASD). After searching different databases, a total of 24 articles were selected. An improvement in the communicative abilities of the participants in all the interventions examined is observed and future lines of research are proposed based on the benefits and limitations found, as well as guidelines for the design of interventions based on scientific evidence.

Keyword: ASD

\section{Introducción}

El concepto del Trastorno del Espectro Autista (TEA) ha ido evolucionando a lo largo del tiempo, siendo el psiquiatra Kanner en 1943, quien acuña por primera vez el término "autismo", entendiendo que era una enfermedad mental con origen en un déficit afectivo. Con la investigación llevada a cabo por Rimland y el Autism Research Institu (ARI), el concepto de autismo pasa a ser considerado como enfermedad mental susceptible de ser intervenida desde la perspectiva de la psiquiatría infantil y evolucionó poco a poco hacia una intervención desde el ámbito educativo. Se ha progresado hacia la idea de un trastorno neurobiológico con sintomatología de déficit en la relación social, el lenguaje, la comunicación y la flexibilidad mental (Alcantud \& Alonso, 2018). Estos mismos autores señalan que el concepto ha ido evolucionando hasta la actualidad. Se considera que las personas con este trastorno tienen capacidad de adaptación, si se les orienta a nivel psicopedagógico y se realizan las adaptaciones necesarias en cada caso, para la individualización del proceso de enseñanza-aprendizaje.

En cuanto al diagnóstico, no se incluyó como patología propia hasta la publicación del DSM-III (APA, 1980), pues era considerado como un tipo de esquizofrenia infantil. Hoy en día, en el DSM-V (APA, 2013), se incluye dentro del Trastorno del Neurodesarrollo, estableciendo tres niveles de gravedad en función de la necesidad de apoyo que precisa 
la persona que presenta el Trastorno del Espectro Autista (TEA) diferenciándose a los que necesitan ayuda, necesitan ayuda notable y necesitan ayuda muy notable. Se considera que es un trastorno que se manifiesta en los tres primeros años de vida y que las áreas afectadas son la interacción social, la comunicación, los intereses y el comportamiento. Respecto a su etiología, se considera que el origen del TEA es multicausal (DSM-V, APA 2013). Por otro lado, se ha demostrado la influencia de factores genéticos en el trastorno, así como factores precipitantes, que son aquellos que afectan al neurodesarrollo, como los gestacionales y los químicos.

Por último, existen teorías cognitivas explicativas del trastorno, como son: la Teoría de la Mente, basada en la dificultad para asignar estados mentales a otras personas como la voluntad o el deseo; la Teoría del déficit en la coherencia central, los afectados por el espectro autista no procesan la información del entorno como una unidad; o la Teoría del déficit en la función ejecutiva, mostrando grandes dificultades para llevar a cabo determinadas conductas y la Teoría afectiva que alega un déficit en el área afectiva.

EI TEA es considerado un trastorno que se produce en un continuo, en el sentido de que a cada individuo le afecta de una manera y en niveles determinados como, por ejemplo, la aparición o no del lenguaje (Junta de Extremadura, 2007).

Las alteraciones que presentan las personas diagnosticadas con TEA son: trastornos en la relación social, trastornos de las funciones comunicativas, trastornos del lenguaje, trastornos de la imaginación, trastornos de la flexibilidad y trastornos del sentido de la actividad. Las alteraciones se encuentran en la conducta, ya que, poseen un humor variable, rabietas, autolesiones, etc. En el desarrollo perceptivo presentando respuestas mejores a estímulos visuales que auditivos y escasa o nula atención a motivación externa. En cuanto al lenguaje y la comunicación manifiestan dificultades en la adquisición del habla, repeticiones, etc. En el desarrollo motor destacan las estereotipias o el retraso motriz. Por lo que respecta al desarrollo cognitivo son frecuentes las dificultades en comprensión del lenguaje, y en algunos casos, va acompañado de discapacidad intelectual. Si se habla de autonomía personal puede encontrarse escaso control de esfínteres, alteraciones del sueño, etc. Y en cuanto al desarrollo social son frecuentes los problemas en la imitación y la ausencia de relaciones sociales, entre otras dificultades.

El ámbito lingüístico ha sido uno de los que mayor interés y estudios ha generado en los últimos tiempos (Marín, Lizcano \& García, 2016a), por las consecuencias que tienen estas limitaciones en la vida diaria y la interferencia que supone para el desarrollo de estos individuos en otros ámbitos, como el social, familiar o profesional. Según Rivière (1999), los niños autistas tienen afectadas las diferentes dimensiones del lenguaje. En lo referente a las dificultades lingüísticas y comunicativas del TEA, se encuentra que suelen manifestarse a partir del tercer mes de vida, mediante conductas prelingüísticas como frecuentes balbuceos, llantos, mutismos, etc. Tal como apunta Tordera (2007), hay dos grupos: aquellos niños que adquieren aspectos sintácticos y fonológicos del lenguaje, pero no pragmáticos y aquellos que directamente no adquieren el lenguaje. Ambos grupos tienen problemas a la hora de comunicarse. Además, tienen alteraciones en otros aspectos de la comunicación como los gestos corporales comunicativos que acompañan al lenguaje oral y facilitan su comprensión.

La intervención de la comunicación y el lenguaje se dirige a potenciar las competencias comunicativas más que las lingüísticas, como: las estrategias para la comunicación verbal o no verbal, ayudar a entender su entorno y a ser entendido, favorecer a la conversación con normas básicas de interacción, facilitar la expresión de necesidades 
básicas y pensamientos y emplear diferentes sistemas de comunicación dependiendo del grado de afectación en el lenguaje.

Algunos de los enfoques y programas de intervención para mejorar las habilidades comunicativas, según García de la Torre (2002), incluyen, por un lado, aquellos programas que están basados en el condicionamiento operante como el de Lovaas. Éste muestra tratamientos para la radicación de conductas inapropiadas como autolesiones o estereotipias y se enseñan estrategias sociales potenciando la adquisición del lenguaje funcional. Por otro lado, el sistema de Comunicación Total (Schaeffer, Musil \& Kollinzas, 1980), desarrollado por Benson Schaeffer, que se basa en el uso simultáneo del habla y el signo para establecer una comunicación con el individuo. Se utilizan también soportes verbales, táctiles y visuales que a medida que se adquieren habilidades por parte de la persona con TEA, pues también se rehabilita la producción de sonidos y palabras a través de la imitación. Por último, la Comunicación Facilitada es un apoyo para el TEA a la hora de expresarse e implica la existencia de una relación entre la persona que le ayuda y el TEA, pues se deberán interpretar las emociones del autista para que sean entendidas por los demás. Alcantud \& Alonso (2018), añaden a los nombrados anteriormente otros enfoques de intervención específicos basados en la comunicación, como el sistema PECS (Bondy \& Frost, 1994), Picture Exchange Communication Systems, se trata de un sistema de comunicación aumentativa y/o alternativa que se centra en el intercambio de imágenes y que permite a los alumnos con TEA sin habilidad lingüística, interaccionar y comunicarse utilizando las imágenes; el enfoque conductual Verbal (VB), que enseña de forma estructurada el lenguaje; y los sistemas de comunicación Aumentativa y/o Alternativa (SAAC), formas distintas de expresarse, que pretende ofrecer apoyo en el lenguaje hablado y en la comunicación del TEA.

La metodología más extendida y eficaz en el TEA desde su propuesta hasta la actualidad es la llevada a cabo por Schopler, denominada TEACCH (Treatment and Education of Autistic Related Communication Handicapped Children), basada en un entorno y rutinas estructuradas con apoyos visuales para reducir la incertidumbre y poder anticipar (Martos \& Paula, 2011). Un estudio reciente de revisión (Sanz-Cervera, Fernández-Andrés, Andrés-Cerezuela \& Tárraga-Minguez, 2018) analiza la efectividad de intervenciones realizadas, desde 2007, basadas en esta metodología en TEA.

Por último, para Gonzales (2014), existen otros enfoques de intervención centrados en la comunicación que se añaden a los ya nombrados, como: estrategias visuales y la instrucción con pistas visuales, que ayudan al individuo a comprender su entorno y desenvolverse en la sociedad a través de fotos, objetos, horarios, etiqueta, etc.; y las historias sociales, descripciones de actitudes apropiadas donde aparece el alumno con TEA en la historia.

\section{Objetivos o hipótesis}

Dada la diversidad de propuestas de intervención existentes, se consideró oportuno y necesario realizar esta revisión para que maestros y otros profesionales de la educación, así como, la comunidad científica en general, puedan diseñar intervenciones basadas en la evidencia científica.

A partir de este contexto se realizó una revisión del estado del arte cuyos objetivos fueron:

- Revisar artículos recientes sobre intervención en comunicación en alumnado con TEA. 
- Analizar la efectividad de las intervenciones para favorecer el desarrollo de la competencia comunicativa en alumnado con TEA en base al éxito en alguna de las dimensiones del lenguaje.

- Realizar propuestas para el diseño de intervenciones basadas en la evidencia.

\section{Métodos}

Para la revisión de artículos, se han utilizado diferentes bases de datos como: Medline, Psycinfo, Google académico y Eric.

Como criterios de inclusión se consideró:

- Idiomas: inglés, español y valenciano.

- Journal Articles, estudios empíricos y estudios cuantitativos.

- Artículos publicados entre 2010 y 2018.

- Palabras clave utilizadas para la búsqueda: "intervention", "communication", "Autism Spectrum Disorder (ASD)" y "early", tanto en inglés, como en español y en valenciano

- Participantes con TEA y edad comprendida entre 0 - 12 años.

Los criterios de exclusión fueron los siguientes:

- intervención no estaba centrada en la mejora de las capacidades comunicativas de alumnado con TEA;

- sujetos sin diagnóstico de TEA o si no se especificaba, como por ejemplo en los trabajos de Brown \& Woods (2016) y Adams, Lockton, Freed, Gaile, Earl, McBean... \& Law (2012);

- $\quad$ estudios anteriores al 2010, como el escrito por Monfort (2009);

- no disponibilidad del artículo completo, como los de: Brown \& Woods (2016), Reichow \& Volkmar (2010), Rose, Trembath, Keen \& Paynter (2016), o el de Dawson, Rogers, Munson, Smith, Winter, Greenson... \& Varley (2010).

- $\quad$ artículos sobre la comunicación y el lenguaje del TEA y no sobre su intervención;

- $\quad$ artículos que no tenían relación con el tema en cuestión;

- revisión bibliográfica, como son los siguientes estudios: Reetzke, Zou, Sheng \& Katsos (2015); Siller, Hutman \& Sigman (2013); Gattino, Riesgo, Longo, Leite \& Faccini (2011); Ramdoss, Lang, Mulloy, Franco, O'Reilly, Didden \& Lancioni (2011); Dawson, Rogers, Munson, Smith, Winter, Greenson... \& Varley (2010); Flippin, Reszka \& Watson (2010); Van der Meer \& Rispoli (2010).

- descripción de intervenciones, como en el estudio de Baixauli-Fortea, Roselló-Miranda, Berenguer-Forner, Colomer-Diago, \& Sevilla (2017);

- duplicación;

- la muestra no era de niños sino de profesionales como terapeutas o patólogos del habla y el lenguaje o de adultos con TEA como en el estudio de Haigh, Walsh, Mazefsky, Minshew \& Eack (2018) o el de Poon \& Sidhu (2017).

Tras aplicar los distintos filtros de inclusión se seleccionaron 11 artículos de Medline, 13 artículos de Psycinfo, 24 artículos de Google académico y 7 artículos de Eric. Finalmente, tras aplicar los filtros de exclusión 24 fueron los artículos seleccionados para la revisión.

\section{Resultados}

En la Tabla 1 se muestra toda la información de los 24 artículos que se han analizado en esta revisión bibliográfica. La tabla incluye: autores y año de publicación, descripción de la muestra (número, sexo, edad y diagnóstico), instrumentos de medida, descripción de la intervención, tipo de estudio y resultados. 
Tabla 1. Resultados

\begin{tabular}{|c|c|c|c|c|}
\hline Autores y año & Descripción de la muestra & Instrumentos de medida y tipo de estudio. & Descripción de la intervención & Resultados \\
\hline $\begin{array}{l}\text { Green, } \\
\text { Charman, } \\
\text { McConachie, } \\
\text { Aldred, Slonims, } \\
\text { Howlin, ... \& } \\
\text { Barrett (2010). }\end{array}$ & $\begin{array}{l}142 \text { alumnos de entre } 2 \text { años } \\
\text { y } 4,11 \text { meses. } \\
77 \text { alumnos realizaron } \\
\text { intervención PACT en } \\
\text { comparación con } 75 \text { que } \\
\text { realizaron el tratamiento } \\
\text { habitual. }\end{array}$ & $\begin{array}{l}\text {-ADOS-G. } \\
\text {-ADOS-G11. } \\
\text {-ADI-R. } \\
\text { Estudio comparativo. }\end{array}$ & $\begin{array}{l}\text { PACT. Utiliza la comunicación con el padre del alumno } \\
\text { para su desarrollo siempre adaptada a sus deficiencias } \\
\text { específicas. Consiste en sesiones en una clínica de } \\
\text { comunicación entre el padre del niño y el terapeuta con } \\
\text { él delante. Con esto, se intenta aumentar la } \\
\text { sensibilidad y la capacidad de respuesta del alumno. }\end{array}$ & $\begin{array}{l}\text { Mejora del lenguaje y la comunicación social de los } \\
\text { alumnos. Mejor interacción padre-hijo e iniciación a } \\
\text { la comunicación. El aumento de la interacción } \\
\text { familiar podría generar un desarrollo comunicativo } \\
\text { en el alumno. }\end{array}$ \\
\hline $\begin{array}{l}\text { Karanth \& } \\
\text { Shaista \& } \\
\text { Srikanth. } \\
\text { (2010). }\end{array}$ & $\begin{array}{l}30 \text { alumnos con TEA, } 21 \\
\text { niños y } 9 \text { niñas entre } 2.2-5.5 \\
\text { años. }\end{array}$ & $\begin{array}{l}\text {-ABA. } \\
\text {-Evaluación de las habilidades de desarrollo: } \\
\text { habilidades motoras gruesas, habilidades } \\
\text { motrices finas, actividades de la vida diaria, } \\
\text { lenguajereceptivo, expresivo y cognitivo, y } \\
\text { habilidades sociales y emocionales. } \\
\text {-Escala de evaluación del autismo infantil } \\
\text { (CARS). } \\
\text { Estudio de campo/programa de intervención. }\end{array}$ & $\begin{array}{l}\text { Programa de intervención temprana para la } \\
\text { comunicación DEALL para TEA. Se realizó en un } \\
\text { periodo de } 10 \text { meses y se proporciona por un equipo de } \\
\text { especialistas en el habla y el lenguaje, terapeutas } \\
\text { ocupacionales y educadores. Se proporcionó durante } \\
3 \text { horas al día, } 5 \text { días a la semana. }\end{array}$ & $\begin{array}{l}\text { Ganancias en habilidades de desarrollo y } \\
\text { disminución en problemas de comportamiento. } \\
\text { Todos los sujetos han demostrado mejoras en } \\
\text { todos los dominios, ni un solo niño ha retrocedido } \\
\text { en su desarrollo. También se observaron } \\
\text { ganancias en las habilidades de comunicación. }\end{array}$ \\
\hline $\begin{array}{l}\text { Yoder, \& } \\
\text { Lieberman } \\
\text { (2010). }\end{array}$ & $\begin{array}{l}36 \text { alumnos entre } 18 \text { y } 60 \\
\text { meses con TEA y usaban } \\
\text { menos de } 10 \text { palabras en su } \\
\text { comunicación, sin problemas } \\
\text { auditivos. Fueron asignados } \\
\text { a uno de los dos } \\
\text { tratamientos, } 19 \text { alumnos a } \\
\text { PECS y } 17 \text { a RPMT. }\end{array}$ & $\begin{array}{l}\text {-Early Social Escalas de comunicación } \\
\text { abreviadas (ESCS). } \\
\text {-Observación por parte de examinadores } \\
\text { ciegos a la asignación en el grupo y al } \\
\text { tratamiento. } \\
\text {-ADOS. } \\
\text { Estudio comparativo. }\end{array}$ & $\begin{array}{l}\text { Comparación de dos intervenciones en comunicación: } \\
\text { - Sistema de comunicación de intercambio de } \\
\text { imágenes (PECS): se basa en la capacidad visual para } \\
\text { personas que tienen déficit en el lenguaje como el TEA. } \\
\text { - Educación receptiva y prelingüística Milieu Teaching } \\
\text { (RPMT): rutinas de juego para dirigirse a } \\
\text { comportamientos de comunicación. }\end{array}$ & $\begin{array}{l}\text { El grupo que recibió intervención PECS aumentó el } \\
\text { número de intercambio de imágenes en } \\
\text { comparación con el grupo de RPMT. }\end{array}$ \\
\hline $\begin{array}{l}\text { Landa, Holman, } \\
\text { O'neill, \& Stuart } \\
\text { (2011). }\end{array}$ & $\begin{array}{l}48 \text { alumnos con TEA de } 21 \text { a } \\
33 \text { meses edad, edad mental } \\
\text { no verbal de al menos } 8 \\
\text { meses, sin hermanos con } \\
\text { TEA. }\end{array}$ & $\begin{array}{l}\text {-MSEL Receptive Language y Puntajes VR T. } \\
\text {-ADOS. } \\
\text {-Evaluación y Programación para Infantes y } \\
\text { Niños (AEPS). } \\
\text {-Grabación en vídeo para comprobar la } \\
\text { frecuencia de comportamientos de } \\
\text { comunicación: } \\
\text {-Lenguaje con gesto de señalar. } \\
\text {-Expresión facial. } \\
\text {-Imitación de acciones. } \\
\text {-Evaluación antes del estudio, en el } \\
\text { seguimiento y al final de este. }\end{array}$ & $\begin{array}{l}\text { Dos grupos reciben tratamiento y se diferencian por la } \\
\text { presencia o ausencia de suplementos: Sincronía } \\
\text { Interpersonal (IS) y Sincronía no interpersonal (no IS). } \\
\text { Se llevó a cabo la enseñanza de un ensayo directo, el } \\
\text { entrenamiento de respuesta, las rutinas basadas en } \\
\text { interacciones y la comunicación aumentativa como las } \\
\text { señales visuales. }\end{array}$ & $\begin{array}{l}\text { Se observaron expresiones faciales, movimientos } \\
\text { de manipulación de objetos con respuesta por } \\
\text { movimiento. } \\
\text { Más imitación social, iniciación de la atención } \\
\text { conjunta y afecto positivo realizada por el IS que } \\
\text { por no IS. Mayor niveles de cognición no verbal } \\
\text { para el grupo IS. } \\
\text { Existieron ganancias sociales, cognitivas y del } \\
\text { lenguaje en ambos grupos. }\end{array}$ \\
\hline
\end{tabular}




\begin{tabular}{|c|c|c|c|c|}
\hline & & Estudio comparativo. & & \\
\hline $\begin{array}{l}\text { Sowden, } \\
\text { Perkins, \& } \\
\text { Clegg (2011). }\end{array}$ & $\begin{array}{l}8 \text { alumnos entre } 2 \text { y } 4 \text { años } \\
\text { con TEA moderado-severo. } 7 \\
\text { varones y } 1 \text { niña. }\end{array}$ & $\begin{array}{l}\text {-Observación de sesiones mediante grabación } \\
\text { para análisis de los datos del contexto de } \\
\text { interacción y estrategias comunicativas. } \\
\text { Programa de intervención. }\end{array}$ & $\begin{array}{l}\text { Intervención naturalista basada en el comportamiento } \\
\text { (NBI) Ilamada programa Explorers, con el objetivo de } \\
\text { aumentar las interacciones y las estrategias de } \\
\text { comunicación. Tuvo una duración de } 3 \text { días por } \\
\text { semana con sesiones de } 2 \text { horas y media. Se trabaja } \\
\text { en cada sesión el juego y las actividades grupales e } \\
\text { individuales, consistió en interacciones adulto-niño e } \\
\text { incluye entrenamiento en el sistema PECS y parte del } \\
\text { programa TEACCH. }\end{array}$ & $\begin{array}{l}\text { Las tareas realizadas grupalmente enfatizaron el } \\
\text { desarrollo social y las tareas funcionales } \\
\text { independientes. Además, se promovió una mayor } \\
\text { comunicación. }\end{array}$ \\
\hline $\begin{array}{l}\text { Van, } \\
\text { Sutherland, } \\
\text { O'Reilly, } \\
\text { Lancioni, \& } \\
\text { Sigafoos (2012). }\end{array}$ & $\begin{array}{l}4 \text { alumnos con TEA en edad } \\
\text { escolar, competencia en } \\
\text { comunicación limitada, sin } \\
\text { impedimentos auditivos o } \\
\text { visuales y con buenas } \\
\text { habilidades motoras. }\end{array}$ & $\begin{array}{l}\text {-Escala de Conducta Adaptativa de Vineland. } \\
\text {-Frecuencia de solicitud correcta de estímulo } \\
\text { con cada AAC. } \\
\text { Estudio comparativo. }\end{array}$ & $\begin{array}{l}\text { Comparación entre la preferencia y la adquisición de un } \\
\text { sistema de comunicación aumentativo y alternativo } \\
\text { (AAC): Firma manual (MS): solicitar estímulos } \\
\text { preferidos con lenguaje de signos. } \\
\text { Intercambio de imágenes (PE): } 4 \text { fotos laminadas de } \\
\text { objetos favoritos con la palabra impresa debajo de la } \\
\text { foto. Dispositivos generadores de habla (SGD): solicitar } \\
\text { estímulos preferidos con dispositivos con imagen- } \\
\text { sonido. }\end{array}$ & $\begin{array}{l}\text { Los } 4 \text { alumnos aprendieron a solicitar un juguete } \\
\text { favorito usando al menos uno de los sistemas de } \\
\text { comunicación. Niño } 1 \text { adquirió SGD y realizó } \\
\text { solicitudes correctas con PE. Niño } 2 \text { eligió PE con } \\
\text { más frecuencia. Niño } 3 \text { eligió con más frecuencia } \\
\text { SGD y lo usó correctamente, al igual que el } \\
\text { sistema PE. Niño } 4 \text { mostró solicitudes correctas } \\
\text { con MS, pero su preferencia era PE. }\end{array}$ \\
\hline $\begin{array}{l}\text { Dykstra, Boyd, } \\
\text { Watson, Crais, } \\
\text { \& Baranek } \\
\text { (2012). }\end{array}$ & $\begin{array}{l}3 \text { alumnos, } 2 \text { niños y una niña } \\
\text { de entre } 3 \text { y } 5 \text { años con TEA } \\
\text { y con necesidades en las } \\
\text { áreas de comunicación social } \\
\text { y juego. }\end{array}$ & $\begin{array}{l}\text {-Cuestionarios escritos. } \\
\text {-ADOS. } \\
\text {-Escala Mullen de A.Temprano. } \\
\text {-Leiter International. } \\
\text {-Performance Scale-Revised. } \\
\text {-Observación por medio de grabación para } \\
\text { rellenar formulario (calificación). } \\
\text {-Sistema de observación de opción múltiple } \\
\text { para estudios experimentales (MOOSES). } \\
\text { Estudio de casos. }\end{array}$ & $\begin{array}{l}\text { Social-Communication And Play (ASAP). Su objetivo es } \\
\text { la mejora de la comunicación social y las habilidades } \\
\text { de juego en alumnos con TEA. Se realiza en sesiones } \\
\text { de uno a uno (alumno y terapeuta) (fase A), en grupo } \\
\text { (fase B) o las dos a la vez (fase C). Se realizan } \\
\text { diferentes actividades como los bloques, el juego } \\
\text { dramático... }\end{array}$ & $\begin{array}{l}\text { Todos los participantes mostraron mejora en } \\
\text { habilidades de comunicación social y juego, esta } \\
\text { mejoría fue más evidente en la última fase (fase C). }\end{array}$ \\
\hline $\begin{array}{l}\text { Ingersoll, \& } \\
\text { Wainer (2013). }\end{array}$ & $\begin{array}{l}8 \text { alumnos con TEA de } 44-80 \\
\text { meses. }\end{array}$ & $\begin{array}{l}\text {-ADOS-G. } \\
\text {-Bayley Scales of Infant Development, } 3^{\mathrm{a}} \text { Ed. } \\
\text {-Escala de Lenguaje Preescolar (PLSIV). } \\
\text {-Observación por medio de grabación de la } \\
\text { realización del programa por parte de los } \\
\text { padres y la conducta infantil durante la } \\
\text { intervención. } \\
\text {-Fidelidad de los padres a la intervención. } \\
\text {-Lenguaje infantil espontáneo. } \\
\text {-Logro de metas. } \\
\text {-Confiabilidad entre observadores. }\end{array}$ & $\begin{array}{l}\text { ImPACT. Intervención mediada por los padres } \\
\text { previamente enseñada por un entrenador donde } \\
\text { utilizan estrategias como el juego y rutinas diarias de } \\
\text { aprendizaje para promover habilidades comunicativas } \\
\text { en sus hijos. Utilizan técnicas de comportamiento } \\
\text { naturalista y desarrollo en sus propias casas. }\end{array}$ & $\begin{array}{l}\text { Mejora general en el desarrollo de la comunicación } \\
\text { social, compromiso social, imitación y el juego } \\
\text { social. Hubo ganancias en el uso del lenguaje } \\
\text { espontáneo por parte de los alumnos } 1,2,3 \text { y } 5 \text {. } \\
\text { Los alumnos } 4 \text { y } 6 \text { redujo su lenguaje espontáneo y } \\
\text { este aumentó cuando sus madres recibieron } \\
\text { estrategias específicas para aumentar el lenguaje } \\
\text { expresivo. Los alumnos } 7 \text { y } 8 \text { se mostraron } \\
\text { indiferentes a la intervención. }\end{array}$ \\
\hline
\end{tabular}




\begin{tabular}{|c|c|c|c|c|}
\hline & & $\begin{array}{l}\text {-LSD de Tukey. } \\
\text { Estudio de casos. }\end{array}$ & & \\
\hline $\begin{array}{l}\text { Houghton, } \\
\text { Schuchard, } \\
\text { Lewis, \& } \\
\text { Thompson } \\
\text { (2013). }\end{array}$ & $\begin{array}{l}12 \text { alumnos. } \\
11 \text { niños y } 1 \text { niña con } \\
\text { diagnóstico de autismo. } \\
\text { Ninguno de ellos presentaba } \\
\text { otro diagnóstico y sus edades } \\
\text { estaban comprendidas entre } \\
\text { los } 48 \text { y } 78 \text { meses. } 6 \text { alumnos } \\
\text { recibieron el tratamiento } \\
\text { intensivo SRP (grupo } \\
\text { experimental) y los otros } 6 \text { y } \\
\text { los otros } 6 \text { no recibieron SRP } \\
\text { (grupo de control). Todos los } \\
\text { alumnos presentaban un } \\
\text { lenguaje expresivo con un } \\
\text { nivel de } 32 \text { meses más o } \\
\text { menos. }\end{array}$ & $\begin{array}{l}\text {-ADOS. } \\
\text {-ADI-R. } \\
\text {-Observación del comportamiento social y } \\
\text { comunicativo (Pruebas de Interacción Pasiva } \\
\text { PIPs): orientación de la cabeza, gesto, } \\
\text { verbalizaciones, duración del episodio de } \\
\text { interacción social y proporción del tiempo } \\
\text { pasado interactuando. } \\
\text { Estudio comparativo. }\end{array}$ & $\begin{array}{l}\text { The Son-Rise Program (SRP). Es una intervención } \\
\text { intensiva ( } 5 \text { días/40 h). Se realiza entre el alumno y el } \\
\text { adulto, en un ambiente natural y sin distracciones con } \\
\text { el objetivo de potenciar la interacción social espontánea } \\
\text { iniciada por el niño. El adulto nunca inicia la interacción } \\
\text { con el alumno, pero responde naturalmente. El adulto } \\
\text { realiza una imitación paralela a lo que hace el alumno } \\
\text { hasta que se consigue el inicio de interacción por parte } \\
\text { de él. }\end{array}$ & $\begin{array}{l}\text { Aumento significativo en el grupo experimental con } \\
\text { SRP de orientaciones con la cabeza, gestos y } \\
\text { comportamiento verbal. En general, los } \\
\text { participantes del grupo experimental presentaban } \\
\text { un aumento de los comportamientos socio- } \\
\text { comunicativos iniciados por el alumno en } \\
\text { comparación con el grupo de control sin aplicación } \\
\text { del SRP, que no presentaron mejoras en el periodo } \\
\text { de realización del PIP sin SRP. }\end{array}$ \\
\hline $\begin{array}{l}\text { Casenhiser, } \\
\text { Shanker, \& } \\
\text { Stieben (2013). }\end{array}$ & $\begin{array}{l}51 \text { alumnos de } 2 \text { años a } 4 \\
\text { años y } 11 \text { meses con TEA. } \\
\text { Asignados aleatoriamente a } \\
\text { dos grupos, uno al que se le } \\
\text { administró el tratamiento } \\
\text { MEHRIT ( } 25 \text { alumnos) y otro } \\
\text { de tratamiento comunitario } \\
\text { (CT) (26 alumnos). }\end{array}$ & $\begin{array}{l}\text {-ADOS. } \\
\text {-Entrevista de diagnóstico de autismo (ADI). } \\
\text {-Grabación en vídeo de la interacción antes y } \\
\text { después de esta. } \\
\text {-Escala de Evaluación del Comportamiento del } \\
\text { Niño (CBRS). } \\
\text {-Escala de lenguaje preescolar IV (PLS). } \\
\text {-Evaluación integral de lenguaje hablado } \\
\text { (CASL). } \\
\text {-MEHRIT Fidelity Scale. } \\
\text { Estudio comparativo. }\end{array}$ & $\begin{array}{l}\text { Iniciativa de Investigación Milton y Ethel Harris } \\
\text { (MEHRIT). Es un modelo basado en el desarrollo social } \\
\text { pragmático y se basa en las mejoras en la interacción } \\
\text { social y comunicación. Utiliza la interacción, la } \\
\text { capacidad del niño para participar e iniciar atención } \\
\text { conjunta y nivel de disfrute del participante } \\
\text { interactuando con el cuidador. }\end{array}$ & $\begin{array}{l}\text { Los participantes con tratamiento MEHRIT } \\
\text { obtuvieron mayores ganancias en habilidades } \\
\text { sociales de interacción social en comparación con } \\
\text { el grupo de tratamiento comunitario (CT). } \\
\text { MEHRIT mejora la calidad de la interacción social } \\
\text { en alumnos y aumenta el disfrute de estas } \\
\text { interacciones con sus familiares. }\end{array}$ \\
\hline Romero (2013). & $\begin{array}{l}\text { Un alumno de } 3 \text { años y } 5 \\
\text { meses con TEA. No hablaba, } \\
\text { no tenía interés por } \\
\text { comunicarse y era poco } \\
\text { sociable. Juega solo, no } \\
\text { existía autonomía en el aseo, } \\
\text { ni en el control de esfínteres, } \\
\text { ni para vestirse o comer. } \\
\text { Presentaba una jerga } \\
\text { ininteligible y emisión de } \\
\text { palabras aisladas. }\end{array}$ & $\begin{array}{l}\text {-Observación de la realización de las } \\
\text { diferentes actividades en la intervención y del } \\
\text { desarrollo de conductas comunicativas. } \\
\text { Estudio de caso. }\end{array}$ & $\begin{array}{l}\text { Intervención basada en potenciar el interés por el } \\
\text { mundo de las otras personas, atención por los objetos } \\
\text { para acabar con el aislamiento social. Se incluyeron en } \\
\text { la intervención actividades como: } \\
\text { - El encajable: se realiza con el adulto y se le da la } \\
\text { pieza del encajable si existe comunicación visual y } \\
\text { expresión verbal. } \\
\text { - Actividades de interés del alumno: el terapeuta lo } \\
\text { acompaña con palabras y entonaciones. } \\
\text { - Saludo y despedida: el terapeuta siempre le saluda y } \\
\text { se despide. }\end{array}$ & $\begin{array}{l}\text { Mejora de la comunicación visual (mirar, sonreír, } \\
\text { esperar señal...) } \\
\text { Iniciación en la etapa verbal. } \\
\text { Búsqueda en el inicio de interacción social en el } \\
\text { juego. } \\
\text { Mejora en tareas de reconocimiento social. } \\
\text { Gesto y expresión oral del saludo y la despedida. }\end{array}$ \\
\hline
\end{tabular}




\begin{tabular}{|c|c|c|c|c|}
\hline $\begin{array}{l}\text { Hill, \& Flores } \\
\text { (2014). }\end{array}$ & $\begin{array}{l}5 \text { alumnos preescolares y de } \\
\text { primaria con TEA. }\end{array}$ & $\begin{array}{l}\text {-Prueba de Desarrollo de Lenguaje-Primaria } \\
\text { (TOLD-P-4). } \\
\text {-Prueba de Desarrollo del Lenguaje Intermedio } \\
\text { (TOLD-I-4). } \\
\text {-Escala de rendimiento revisada. } \\
\text {-Grabación en vídeo de las sesiones para la } \\
\text { recolecta de datos (comportamientos } \\
\text { asociados con PECS y iPad). } \\
\text { Estudio comparativo. }\end{array}$ & $\begin{array}{l}\text { Intervención comparativa entre las intervenciones de } \\
\text { comunicación aumentativas o alternativas (AAC) PECS } \\
\text { y iPad: } \\
\text { PECS: sistema de comunicación de intercambio de } \\
\text { imágenes con estrategia de comunicación alternativa, } \\
\text { con preferencia del procesamiento visual y enseña } \\
\text { habilidades de comunicación funcional. } \\
\text { iPad: con la utilización de una aplicación concreta como } \\
\text { Proloquo2Go para facilitar su uso como un sistema de } \\
\text { comunicación. Proporciona comunicación aumentativa } \\
\text { y alternativa (AAC), posee voces de texto a voz, } \\
\text { imágenes y símbolos de color y un vocabulario muy } \\
\text { amplio. La intervención consistía en } 21 \text { días, con } 3 \\
\text { sesiones diarias y } 5 \text { días a la semana. }\end{array}$ & $\begin{array}{l}\text { Evolución en la enseñanza de habilidades } \\
\text { comunicativas para los estudiantes. Uno de los } \\
\text { alumnos realizaba iniciaciones y solicitudes más } \\
\text { independientes con imágenes. Otro demostró más } \\
\text { solicitaciones usando el iPad con la aplicación } \\
\text { Proloquo2go. Dos estudiantes mostraron una } \\
\text { cantidad mayor de solicitudes iniciadas con el iPad. } \\
\text { Tanto PECS como iPad influyeron en el aumento } \\
\text { del comportamiento verbal de un alumno. Cada } \\
\text { alumno respondió de manera diferente a cada } \\
\text { intervención de comunicación. } \\
\text { Fue más fácil la aplicación de PECS que iPad. }\end{array}$ \\
\hline $\begin{array}{l}\text { Kasari, Kaiser, } \\
\text { Goods, Nietfeld, } \\
\text { Mathy, Landa, } \\
\text {.. \& Almirall } \\
\text { (2014). }\end{array}$ & $\begin{array}{l}61 \text { alumnos mínimamente } \\
\text { verbales con TEA de } 5 \text { a } 8 \\
\text { años, al menos } 2 \text { años de } \\
\text { intervención anterior al } \\
\text { tratamiento y el lenguaje de } \\
\text { una edad de al menos } 24 \\
\text { meses. }\end{array}$ & $\begin{array}{l}\text {-El lenguaje de referencia (NLS). } \\
\text { - Emisiones comunicativas espontáneas } \\
\text { (TSCU). } \\
\text {-Total de palabras diferentes (TDWR). } \\
\text {-Número de comentarios (TCOM). } \\
\text {-Total de emisiones que fueron socialmente } \\
\text { comunicativas (PSCU). } \\
\text {-Palabras por minuto (WPM). } \\
\text {-Longitud media del enunciado en palabras } \\
\text { (MLUw). } \\
\text {-Leiter International. } \\
\text {-Leiter-R. } \\
\text {-Peabody Picture Vocabulary Test (PPVT-4). } \\
\text {-Prueba del desarrollo temprano del lenguaje } \\
\text { (TELD-3). } \\
\text { Estudio comparativo. }\end{array}$ & $\begin{array}{l}\text { Intervenciones utilizadas: } \\
\text {-JASPER: atención simbólica Play Engagement and } \\
\text { Regulation: Se basa en los gestos prelingüísticos y } \\
\text { competencias en el juego. } \\
\text {-EMT: enhanced Milieu Teaching: Se basa en las } \\
\text { respuestas de interacción y en la incitación al lenguaje } \\
\text { espontáneo. } \\
\text { Los alumnos fueron asignados aleatoriamente a dos } \\
\text { tipos de intervención (JASP+EMT con o sin un } \\
\text { dispositivo generador de voz (SGD), en los dos tipos se } \\
\text { asignó un terapeuta. La intervención sin SGD } \\
\text { (JASP+EMT) se centró en la atención conjunta, el } \\
\text { lenguaje funcional durante los juegos favoritos del } \\
\text { participante y el juego simbólico. }\end{array}$ & $\begin{array}{l}\text { Se encontraron mejoras la comunicación } \\
\text { espontánea, realización de enunciados, palabras } \\
\text { nuevas y comentarios con el tipo de intervención } \\
\text { que combina el SGD (JASP+EMT+SGD). } \\
\text { Los alumnos asignados a JASP+EMT+SGD } \\
\text { tuvieron una tasa de respuesta más alta que en } \\
\text { JASP+EMT. }\end{array}$ \\
\hline $\begin{array}{l}\text { Van der Paelt, } \\
\text { Warreyn \& } \\
\text { Roeyers (2014). }\end{array}$ & $\begin{array}{l}85 \text { alumnos con TEA, de } \\
\text { entre } 22 \text { y } 75 \text { meses fueron } \\
\text { divididos en tres grupos de } \\
\text { intervención. }\end{array}$ & $\begin{array}{l}\text {-Bayley Scales of Infant Development. } \\
\text {-Wechsler Preschool and Primary Scale of } \\
\text { Intelligence, WPPSI-III. } \\
\text {-Prueba de inteligencia no verbal Snijders- } \\
\text { Oomen-Revisado. } \\
\text {-Perfil Psicoeducativo-Revisado. } \\
\text {-McCarthy Developmental Scales. } \\
\text {-ADOS. } \\
\text { - Hitos de comportamiento verbal (VB-Mapp). } \\
\text {-Cuestionario a los terapeutas. }\end{array}$ & $\begin{array}{l}\text { Intervención basada en el análisis del comportamiento } \\
\text { aplicado con un programa de intervención específico } \\
\text { dirigido a la imitación y a la atención conjunta, en } \\
\text { comparación con un tratamiento habitual (TAU) y la } \\
\text { intervención basada en ABA. Se comparó el efecto de } \\
\text { distintos métodos de intervención: } \\
\text { ABA: entrenamiento basado en el comportamiento } \\
\text { verbal (solicitar, nombres de objetos, imitaciones, } \\
\text { responder, etc.) Sus objetivos son comunicativos. } \\
\text { Imitación/intervención de atención conjunta: } 24 \\
\text { sesiones de actividades para estimular la imitación con }\end{array}$ & $\begin{array}{l}\text { Aumento significativo en imitación, en el juego } \\
\text { social, en lenguaje receptivo y expresivo y } \\
\text { disminución de síntomas de Autismo en todos los } \\
\text { participantes. La mayoría de los alumnos } \\
\text { mostraron un progreso independientemente de la } \\
\text { intervención aplicada, otros no. No se encontraron } \\
\text { diferencias significativas en relación con la } \\
\text { comunicación social entre los grupos de } \\
\text { intervención. }\end{array}$ \\
\hline
\end{tabular}




\begin{tabular}{|c|c|c|c|c|}
\hline & & $\begin{array}{l}\text {-Grabaciones en vídeo de una sesión de } \\
\text { intervención. } \\
\text {-La escala preescolar de imitación y praxis } \\
\text { (PIPS). } \\
\text { - Juego de simulación (ToPP). } \\
\text { - Comunicación Social Temprana Escalas } \\
\text { (ESCS). } \\
\text {-Escalas del Lenguaje del Desarrollo de } \\
\text { Reynell (RTOS). } \\
\text {-Escalas de comportamiento adaptativo de } \\
\text { Vineland. } \\
\text {-Lista de verificación de comportamiento } \\
\text { infantil. } \\
\text { Estudio comparativo. }\end{array}$ & $\begin{array}{l}\text { diferentes acciones con objetos, movimientos } \\
\text { corporales o gestos. } \\
\text { TAU: se basa en el modelo TEACCH, es decir, en el } \\
\text { entrenamiento de habilidades sociales. }\end{array}$ & \\
\hline $\begin{array}{l}\text { Radley, Jenson, } \\
\text { Clark, Hood, \& } \\
\text { Nicholas (2014). }\end{array}$ & $\begin{array}{l}2 \text { alumnos, } 1 \text { niño y } 1 \text { niña de } \\
4.9 \text { años y } 4.8 \text { años con TEA. }\end{array}$ & $\begin{array}{l}\text {-ADOS. } \\
\text {-Grabación en vídeo de periodos de juego } \\
\text { libres en intervención. } \\
\text {-Compromiso social del alumno con TEA con } \\
\text { compañero (dar, compartir, mostrar objetos o } \\
\text { juguetes, conversar, respetar turno o jugando). } \\
\text { Programa de intervención. }\end{array}$ & $\begin{array}{l}\text { Programa Superhéroes Social Skills, intervención de } \\
\text { habilidades sociales con la aplicación de diferentes } \\
\text { pruebas para abordar habilidades de participación } \\
\text { social con otros alumnos, pruebas como: inclusión de } \\
\text { compañeros con desarrollo normativo que hacen la } \\
\text { función de modelo en el uso de habilidades sociales; } \\
\text { vídeo donde se incluyen habilidades sociales como } \\
\text { objetivo; autocontrol de habilidades y narrativas } \\
\text { sociales (cómic y libros). }\end{array}$ & $\begin{array}{l}\text { La intervención contribuyó a una mayor interacción } \\
\text { de los alumnos con TEA con sus iguales en el } \\
\text { juego libre. Aumentaron las iniciaciones y } \\
\text { respuestas con sus compañeros y también en las } \\
\text { iniciativas sociales incluso después del tratamiento, } \\
\text { en el periodo de seguimiento de } 2 \text { semanas. } \\
\text { Incrementos en general de comportamientos } \\
\text { sociales. }\end{array}$ \\
\hline $\begin{array}{l}\text { Fortea, } \\
\text { Escandell, } \\
\text { Castro, Martos } \\
\text { (2015). }\end{array}$ & $\begin{array}{l}30 \text { sujetos. } 25 \text { niños y } 5 \text { niñas } \\
\text { con TEA entre } 18-30 \text { meses } \\
\text { sin lenguaje oral. }\end{array}$ & $\begin{array}{l}\text {-ADOS. } \\
\text {-ADIR. } \\
\text {-Prueba de Lenguaje Oral de Navarra } \\
\text { Revisada (PLON-R). } \\
\text {-Programa SPSS-Statistics } 19 . \\
\text { Estudio de campo/programa de intervención. }\end{array}$ & $\begin{array}{l}\text { Programa de intervención para la mejora del lenguaje } \\
\text { usando sistemas aumentativos de comunicación } \\
\text { (SAAC) que combinan palabra + apoyo visual: el } \\
\text { programa de comunicación total (PCT) con terapeuta y } \\
\text { el programa de comunicación por intercambio de } \\
\text { imágenes (PECS) para el entrenamiento del } \\
\text { participante con TEA. Algunos de los objetivos para el } \\
\text { lenguaje y la comunicación de estos alumnos fueron: } \\
\text { señalas y vocalizar al mismo tiempo, imitar sílabas y } \\
\text { sonidos, discriminar sí-no, ayuda a la imitación de } \\
\text { sonidos y palabras y potenciar el lenguaje oral } \\
\text { espontáneo. La intervención se llevó a cabo en una } \\
\text { media de cuatro sesiones semanales de } 45 \text { minutos } \\
\text { durante un año con ayuda de los padres en una } \\
\text { escuela con sesiones semanales de } 2 \text { horas en } 6 \\
\text { semanas seguidas. }\end{array}$ & $\begin{array}{l}\text { El uso de sistemas de comunicación aumentativa y } \\
\text { alternativa (SAAC) mejora la evolución del } \\
\text { desarrollo lingüístico y comunicativo pues toda la } \\
\text { muestra ha desarrollado un lenguaje oral en cierta } \\
\text { medida un año después. La mitad de la muestra } \\
\text { mejora en componente "forma" del PLON-R, que } \\
\text { valúa fonología, morfología y sintaxis. En el } \\
\text { componente "contenido" que evalúa el léxico de } \\
\text { conceptos espaciales, corporales, colores y } \\
\text { vocabulario básico, } 22 \text { alumnos han evolucionado y } \\
14 \text { han alcanzado una puntuación media. En el } \\
\text { componente "uso" que evalúa funciones } \\
\text { comunicativas, } 24 \text { alumnos han mejorado y más de } \\
\text { la mitad han alcanzado un desarrollo normal. }\end{array}$ \\
\hline
\end{tabular}




\begin{tabular}{|c|c|c|c|c|}
\hline $\begin{array}{l}\text { Chang, Shire, } \\
\text { Shih, Gelfand, \& } \\
\text { Kasari (2016). }\end{array}$ & $\begin{array}{l}66 \text { alumnos en preescolar } \\
\text { (entre } 3 \text { y } 5 \text { años) con TEA. } \\
\text { La mayoría de ellos eran } \\
\text { niños. }\end{array}$ & $\begin{array}{l}\text {-ADOS-2. } \\
\text {-Escala Mullen de aprendizaje temprano } \\
\text { (MSEL). } \\
\text {-Programa de evaluación y ubicación de hitos } \\
\text { de comportamiento verbal (VB-MAPP). } \\
\text {-Evaluación de dominios cognitivos: lenguaje } \\
\text { expresivo y receptivo, motricidad fina y } \\
\text { percepción visual. } \\
\text {-Observación mediante grabaciones de las } \\
\text { interacciones maestro-niño. } \\
\text {-Escala temprana de comunicación social } \\
\text { (ESCS). } \\
\text {-Evaluación del juego estructurado (SPA). } \\
\text {-Pruebas de Wilcoxon. } \\
\text { Estudio comparativo. }\end{array}$ & $\begin{array}{l}\text { Intervención de comunicación social, Play Engagement } \\
\text { and Regulation (JASPER). Se realizó en } 12 \text { aulas con } \\
12 \text { profesores diferentes, se separó a los alumnos para } \\
\text { recibir intervención JASPER (IT) o en lista de espera } \\
\text { (ML). JASPER se basa en la comunicación y la } \\
\text { atención conjunta simbólica con actividades como el } \\
\text { juego simbólico, el juego independiente, comunicación, } \\
\text { otras actividades independientes y la hora de merienda. } \\
\text { Se realizaron juguetes para la intervención como una } \\
\text { cocina, muñecas, coches y bloques. }\end{array}$ & $\begin{array}{l}\text { Los alumnos que recibieron JASPER demostraron } \\
\text { una mayor comunicación social, mayores puntajes } \\
\text { de lenguaje y cognitivos en comparación en el } \\
\text { grupo de control en lista de espera (ML). } \\
\text { El grupo JASPER (IT) mantuvo el efecto del } \\
\text { tratamiento después del mes de seguimiento. } \\
\text { Los alumnos del grupo JASPER pasaron más } \\
\text { tiempo en juego funcional. Además los alumnos } \\
\text { que recibieron JASPER mostraron aumentos en } \\
\text { atención conjunta, gestos, lenguaje, articulación } \\
\text { iniciada y duración de las interacciones con sus } \\
\text { maestros, en comparación con el grupo en lista de } \\
\text { espera. }\end{array}$ \\
\hline $\begin{array}{l}\text { Srinivasa, } \\
\text { Eigsti, Gifford \& } \\
\text { Bhat (2016). }\end{array}$ & $\begin{array}{l}36 \text { alumnos en edad escolar } \\
\text { (5-12 años) con TEA, que } \\
\text { fueron asignados } \\
\text { aleatoriamente a los tres } \\
\text { grupos (12 alumnos por } \\
\text { grupo). }\end{array}$ & $\begin{array}{l}\text {-Prueba estandarizada de comunicación } \\
\text { receptiva. } \\
\text {-Prueba estandarizada de habilidades de } \\
\text { comunicación. } \\
\text {-Prueba estandarizada de atención conjunta } \\
\text { (JTAT). } \\
\text {-Medición de la capacidad de respuesta a las } \\
\text { ofertas sociales. } \\
\text {-Medición del entrenamiento de } \\
\text { vocalización/verbalización. } \\
\text {-ANCOVA. } \\
\text {-ANOVA. } \\
\text {-Duración de la verbalización. } \\
\text {-Intervalos de confianza. } \\
\text { Ensayo piloto aleatorizado controlado } \\
\text { comparativo. }\end{array}$ & $\begin{array}{l}\text { Comparación de } 8 \text { semanas ( } 32 \text { sesiones) de } \\
\text { intervención entre tres grupos: } \\
\text { Grupo con robot: intervención con juegos de imitación } \\
\text { de cuerpo, interacción social con juegos de saludo y } \\
\text { despedida, juegos de acción y para caminar. } \\
\text { Grupo de ritmo: intervención con música, interacción } \\
\text { social con canciones de saludo y despedida imitación, } \\
\text { sonidos, ritmo, melodía, acción de la canción y juego } \\
\text { dinámico. } \\
\text { Grupo de comparación: intervención con actividades de } \\
\text { habilidades académicas comunicativas que se realizan } \\
\text { en la escuela, interacción social con juegos de saludo y } \\
\text { despedida... }\end{array}$ & $\begin{array}{l}\text { Tras la intervención, el grupo de ritmo mostró un } \\
\text { aumento en al número de palabras expresadas. } \\
\text { El grupo de robots tubo una mayor vocalización } \\
\text { dirigida por el entrenador en comparación con los } \\
\text { otros grupos. } \\
\text { El grupo de ritmo y de comparación tuvo un } \\
\text { aumento en la verbalización social espontánea, } \\
\text { pero el grupo de robot pasó más tiempo hablando. } \\
\text { Se observaron mejoras en el grupo de ritmo en las } \\
\text { medidas estandarizadas de capacidad de } \\
\text { comunicación. }\end{array}$ \\
\hline $\begin{array}{l}\text { Barber, Saffo, } \\
\text { Gilpin, Craft \& } \\
\text { Goldstein } \\
\text { (2016). }\end{array}$ & $\begin{array}{l}6 \text { alumnos. } 3 \text { alumnos con } \\
\text { TEA y } 3 \text { con desarrollo típico } \\
\text { en edades comprendidas } \\
\text { entre } 4-5 \text { años, se } \\
\text { emparejaron formando } 3 \\
\text { parejas. } \\
\text { Alumno TEA 1: Niño de } 8 \\
\text { años. } \\
\text { Alumno TEA 2: Niño de } 4 \\
\text { años. }\end{array}$ & $\begin{array}{l}\text {-ADOS. } \\
\text {-Compuesto de Afecto Social, Conducta } \\
\text { Restringida y Repetitiva (SARRB). } \\
\text {-Mullen Early Learning Composite. } \\
\text {-Grabaciones de cada sesión para codificar el } \\
\text { número y la calidad de las iniciaciones sociales } \\
\text { y respuestas a través de } 3 \text { niveles de } \\
\text { comunicación. } \\
\text {-Early Communicative Index (ECI). }\end{array}$ & $\begin{array}{l}\text { Stay Play Talk es una intervención mediada por pares } \\
\text { (PMI). Se emparejó un participante con desarrollo típico } \\
\text { a cada uno de los alumnos con TEA. Se les enseñó a } \\
\text { los alumnos sin TEA a jugar, hablar y permanecer con } \\
\text { su amigo con TEA. Se realizó con el objetivo de } \\
\text { examinar la frecuencia de iniciaciones sociales y } \\
\text { respuestas de los alumnos con TEA mediante una } \\
\text { interacción con un igual. }\end{array}$ & $\begin{array}{l}\text { Tanto los alumnos con TEA como los de desarrollo } \\
\text { típico mostraron mejoras en la frecuencia de sus } \\
\text { respuestas y las interacciones sociales verbales y } \\
\text { no verbales después de la intervención. Aumento } \\
\text { en la comunicación general para todos los } \\
\text { participantes. }\end{array}$ \\
\hline
\end{tabular}




\begin{tabular}{|c|c|c|c|c|}
\hline & $\begin{array}{l}\text { Alumno TEA 3: Niño de } 3 \\
\text { años. }\end{array}$ & $\begin{array}{l}\text {-Simulación Análisis de modelado (SMA). } \\
\text { Programa de intervención. }\end{array}$ & & \\
\hline $\begin{array}{l}\text { Krstovska \& } \\
\text { Jones (2016). }\end{array}$ & $\begin{array}{l}4 \text { niños con TEA de entre } 20 \\
\text { y } 30 \text { meses. }\end{array}$ & $\begin{array}{l}\text {-ADOS. } \\
\text {-DAYC. } \\
\text {-Escala de Comunicación Social Temprana } \\
\text { (ESCS). } \\
\text {-Grabación de sesiones. Programa de } \\
\text { intervención. }\end{array}$ & $\begin{array}{l}\text { Intervención en la comunicación social que indica unas } \\
\text { pautas y refuerzo para enseñar desplazamiento en la } \\
\text { mirada del participante con TEA para responder a una } \\
\text { solicitud y nombre e iniciar la atención conjunta y una } \\
\text { solicitud. La intervención duró de 3-9 semanas. Se } \\
\text { utilizaron } 30 \text { juguetes diferentes (rompecabezas, } \\
\text { bloques, libros u otros objetos). }\end{array}$ & $\begin{array}{l}\text { Mostraron un mayor comportamiento de } \\
\text { comunicación social (demanda social y aumento de } \\
\text { sonrisa). }\end{array}$ \\
\hline $\begin{array}{l}\text { Neri \& Romero } \\
\text { (2017). }\end{array}$ & $\begin{array}{l}3 \text { estudiantes con déficits en } \\
\text { comunicación y habilidades } \\
\text { sociales, con edades de entre } \\
\text { 4-8 años. }\end{array}$ & $\begin{array}{l}\text {-Peabody. } \\
\text {-Prueba de combinación de preguntas. } \\
\text {-Capacidad de identificar una emoción } \\
\text { particular, capacidad de unir emociones } \\
\text { similares, capacidad de elegir la emoción } \\
\text { apropiada en función de un escenario } \\
\text { concreto. } \\
\text {-Grabación en vídeo de sesiones. } \\
\text { Estudio de casos/programa de intervención. }\end{array}$ & $\begin{array}{l}\text { Programa de intervención en computadora (The } \\
\text { Transporters). Intervención basada en el } \\
\text { reconocimiento y comprensión de emociones y } \\
\text { expresiones faciales utilizando la informática. El } \\
\text { programa consta de } 15 \text { episodios que duran } 5 \text { minutos } \\
\text { cada uno y se muestran rostros de personajes en } \\
\text { diferentes transportes (tren, barco, etc.) Los episodios } \\
\text { son narrados y los personajes no hablan para que los } \\
\text { alumnos solo se centren en su expresión facial. }\end{array}$ & $\begin{array}{l}\text { Todos los alumnos mostraron mejoras en las } \\
\text { medidas de reconocimiento de emociones en las } \\
\text { caras y se mantuvo esta habilidad un mes después } \\
\text { de la intervención. Mejor rendimiento en } \\
\text { comprensión de los pensamientos y emociones de } \\
\text { los demás. }\end{array}$ \\
\hline $\begin{array}{l}\text { Bradsha, } \\
\text { Koegel \& } \\
\text { Koegel (2017). }\end{array}$ & $\begin{array}{l}3 \text { alumnos de } 15 \text { meses, } 17 \\
\text { meses y } 21 \text { meses con } \\
\text { retrasos en la comunicación } \\
\text { social con TEA. }\end{array}$ & $\begin{array}{l}\text {-Escala de Conducta Adaptativa de Vineland. } \\
\text {-ADOS-T. } \\
\text {-Mullen Scales or Early Learning. } \\
\text {-Motor Skills. } \\
\text {-Grabación en vídeo de sesiones de } \\
\text { interacción padres-hijos. } \\
\text { Programa de intervención. }\end{array}$ & $\begin{array}{l}\text { Intervención mediada por padres para la mejora de la } \\
\text { comunicación expresiva (PRT). Esta intervención busca } \\
\text { la motivación utilizando métodos naturalistas. Analiza el } \\
\text { cambio en la comunicación expresiva durante } 12 \\
\text { semanas. Se realizaron sesiones iniciales donde los } \\
\text { padres jugaron e interactuaron con su hijo como lo } \\
\text { hacen normalmente. Se basa en seguir la iniciativa del } \\
\text { alumno, obtener su atención, dar indicaciones sobre el } \\
\text { lenguaje, proporcionar refuerzo inmediato con los } \\
\text { intentos de comunicación. }\end{array}$ & $\begin{array}{l}\text { La comunicación verbal mejoró en todos los } \\
\text { participantes y los síntomas de autismo } \\
\text { disminuyeron. Se observó mayor competencia } \\
\text { lingüística y los tres alumnos demostraron } \\
\text { ganancias en la comunicación verbal. Aumentaron } \\
\text { las respuestas a las preguntas del cuidador. }\end{array}$ \\
\hline $\begin{array}{l}\text { Muzammal \& } \\
\text { Jones (2017). }\end{array}$ & $\begin{array}{l}3 \text { alumnos (dos niños y } 1 \\
\text { niña) de 2-3 años } \\
\text { diagnosticados con TEA. }\end{array}$ & $\begin{array}{l}\text {-Duración de las interacciones. } \\
\text {-Escalas Mullen de aprendizaje temprano } \\
\text { (Mullen). } \\
\text { - Escala de lenguaje preescolar (PLS-4). } \\
\text {-Escala de lenguaje de Rossetti Infant-Toddler } \\
\text { (Rossetti 2006). } \\
\text {-AYUDA. } \\
\text {-Evaluación de niños pequeños (DAYC). } \\
\text {-Grabación de parte de las sesiones. } \\
\text { Programa de intervención. }\end{array}$ & $\begin{array}{l}\text { Intervención en comunicación social basada en la } \\
\text { mirada en contextos comunicativos con } \\
\text { intervencionistas y con familiares. Involucró } \\
\text { indicaciones y refuerzo, se enseña a los alumnos a } \\
\text { utilizar la mirada para solicitar juguetes preferidos. } \\
\text { Sesiones en casa del niño durante } 3-4 \text { días por semana } \\
\text { con 2-3 sesiones por día. Los materiales utilizados } \\
\text { fueron un grupo de juguetes preferidos del alumno para } \\
\text { que los solicite y utilice la atención conjunta. }\end{array}$ & $\begin{array}{l}\text { Mejora en los tres alumnos de respuesta a una } \\
\text { solicitud, inicios de solicitud y respuesta a la } \\
\text { atención conjunta. Los tres alumnos mostraron } \\
\text { aumentos en la frecuencia del contacto visual } \\
\text { después de la intervención. }\end{array}$ \\
\hline
\end{tabular}




\begin{tabular}{|c|c|c|c|c|}
\hline Rollins (2018). & $\begin{array}{l}34 \text { alumnos con edades de } \\
\text { menos de } 40 \text { meses con TEA } \\
\text { y sin ningún otro trastorno. }\end{array}$ & $\begin{array}{l}\text {-ADOS-2. } \\
\text {-Vineland Adaptive BehaviorScales II (VABS } \\
\text { II). } \\
\text {-Escala de aprendizaje infantil (MSEL). } \\
\text {-Parenting Stress Index-4 (PSI-4). } \\
\text {-Grabaciones de sesiones durante } 10 \text { min con } \\
\text { iPad. } \\
\text {-Lentes ocultos que usaron los padres para } \\
\text { capturar el contacto visual del niño. } \\
\text {-Sistema de Intercambio de Datos de Lengua } \\
\text { Infantil (CHILDES). } \\
\text {-Inventario de actos comunicativos-abreviados } \\
\text { (INCA-A). } \\
\text { Ensayo de control aleatorio (ECA)/ } \\
\text { comparativo. }\end{array}$ & $\begin{array}{l}\text { Pathways Early Autism Intervention (Pathways). } 12 \\
\text { semanas de intervención. Es una intervención } \\
\text { conductual del desarrollo naturalista (NDBI) realizada } \\
\text { por los padres para que trabaja el contacto visual social } \\
\text { y la comunicación mediante el juego, además se centra } \\
\text { en el déficit emocional compartido central de los TEA. } \\
\text { Esta intervención se comparó con dos grupos de } \\
\text { control (uno sin mirada social y otro (BAU) con } \\
\text { servicios públicos para TEA). Tres grupos para } \\
\text { evaluación final (ruta con mirada social, intervención sin } \\
\text { mirada social y BAU). }\end{array}$ & $\begin{array}{l}\text { El grupo Pathways con mirada social potenció el } \\
\text { uso de esta en los alumnos en comparación con } \\
\text { los otros dos grupos y mejoraron su rendimiento en } \\
\text { reciprocidad verbal después de la intervención. No } \\
\text { se encontraron diferencias características entre los } \\
\text { dos grupos de control. } \\
\text { Quien recibió intervención Pathways obtuvo } \\
\text { ganancias pragmáticas sociales por una mayor } \\
\text { mirada social compartida, en comparación con los } \\
\text { otros grupos. }\end{array}$ \\
\hline $\begin{array}{l}\text { Rollins, P. R. } \\
(2018) .\end{array}$ & $\begin{array}{l}34 \text { alumnos con edades de } \\
\text { menos de } 40 \text { meses con TEA } \\
\text { y sin ningún otro trastorno. }\end{array}$ & $\begin{array}{l}\text {-ADOS-2. } \\
\text {-Vineland Adaptive BehaviorScales II (VABS } \\
\text { II). } \\
\text {-Escala de aprendizaje infantil (MSEL). } \\
\text {-Parenting Stress Index-4 (PSI-4). } \\
\text {-Grabaciones de sesiones durante } 10 \text { min con } \\
\text { iPad. } \\
\text {-Lentes ocultos que usaron los padres para } \\
\text { capturar el contacto visual del niño. } \\
\text {-Sistema de Intercambio de Datos de Lengua } \\
\text { Infantil (CHILDES). } \\
\text {-Inventario de actos comunicativos-abreviados } \\
\text { (INCA-A). } \\
\text {-ANOVA. }\end{array}$ & $\begin{array}{l}\text { Pathways Early Autism Intervention (Pathways). } 12 \\
\text { semanas de intervención. Es una intervención } \\
\text { conductual del desarrollo naturalista (NDBI) realizada } \\
\text { por los padres para alumnos con TEA que trabaja el } \\
\text { contacto visual social entre padres e hijos para mejorar } \\
\text { su comunicación mediante el juego, además se centra } \\
\text { en el déficit emocional compartido central de los TEA. } \\
\text { Esta intervención se comparó con dos grupos de } \\
\text { control (uno sin mirada social y otro (BAU) con } \\
\text { servicios públicos para TEA). Tres grupos para } \\
\text { evaluación final (ruta con mirada social, intervención sin } \\
\text { mirada social y BAU). }\end{array}$ & $\begin{array}{l}\text { El grupo Pathways con mirada social potenció el } \\
\text { uso de esta en los alumnos en comparación con } \\
\text { los otros dos grupos y mejoraron su rendimiento en } \\
\text { reciprocidad verbal después de la intervención. No } \\
\text { se encontraron diferencias características entre los } \\
\text { dos grupos de control. } \\
\text { Quien recibió intervención Pathways obtuvo } \\
\text { ganancias pragmáticas sociales por una mayor } \\
\text { mirada social compartida, en comparación con los } \\
\text { otros grupos. }\end{array}$ \\
\hline
\end{tabular}


Los artículos que han sido analizados muestran que las intervenciones son efectivas para la mejora de la comunicación en alumnado con TEA. Mejoran específicamente la interacción social (Houghton, Schuchard, Lewis, \& Thompson, 2013; Casenhiser, Shanker, \& Stieben, 2013; Romero, 2013; Srinivasan, Eigsti, Gifford, \& Bhat, 2016) o el lenguaje formal y funcional (Green, Charman, McConachie, Aldred, Slonims, Howlin, ... \& Barrett, 2010; Landa, Holman, O'neill, \& Stuart, 2011; Ingersoll, \& Wainer, 2013; Van der Paelt, Warreyn \& Roeyers, 2014; Chang, Shire, Shih, Gelfand, \& Kasari, 2016).

Algunos de los programas de intervención analizados utilizan la comunicación entre familiar y niño con TEA (Green, Charman, McConachie, Aldred, Slonims, Howlin, ... \& Barrett, 2010; Bradshaw, Koegel \& Koegel, 2017), otros utilizan aparatos electrónicos como el ordenador o el iPad (Hill \& Flores, 2014; Neri, Romero, 2017). Además, es muy corriente la utilización de PECS u otros sistemas aumentativos de la comunicación (Yoder, \& Lieberman, 2010; Van, Sutherland, O'Reilly, Lancioni, \& Sigafoos, 2012; Hill \& Flores, 2014; Fortea, Escandell, Castro \& Martos, 2015). Los estudios revisados concluyen que a través de las intervenciones específicas para la comunicación del TEA mediante programas o técnicas como PECS, TEACCH o generadores de voz, existe una mejora significativa en todos los aspectos y, en la mayoría de casos, tanto a nivel de comportamiento verbal como en habilidades comunicativas para la interacción social.

Además, los programas de intervención utilizados para esta revisión bibliográfica muestran resultados positivos en los comportamientos sociales de los participantes, pues todos los programas trabajan habilidades sociales diferentes que favorecen la comunicación y la interacción social en el TEA. Por otra parte, todas son intervenciones tempranas, periodo en el que se han demostrado que se favorece la adquisición de habilidades.

\section{Discusión}

Tras realizar el análisis de los artículos incluidos en esta revisión bibliográfica se puede concluir que las intervenciones muestran resultados positivos en los participantes.

Las intervenciones son efectivas para el desarrollo de la competencia comunicativa mediante el componente verbal o no verbal, pues todos los tratamientos analizados muestran resultados positivos en relación con esta competencia. Alguna de las intervenciones ayuda específicamente a la interacción social con mejora de sus capacidades conversacionales (Chang, Shire, Shih, Gelfand \& Kasari, 2016) y otros con el aumento del interés por relacionarse con el mundo (Radley, Jenson, Clark, Hood \& Nicholas, 2014). Otras de las intervenciones se centran en la expresión de necesidades básicas, sentimientos y pensamientos de manera verbal o no verbal (Hill \& Flores, 2014). En la mayoría de las rehabilitaciones que se han analizado, se potencia la integración en la escuela y en la sociedad, ya que la mejora de la comunicación promueve acabar con el problema del aislamiento social (Romero, 2013). Además, todos los tratamientos encontrados se aplican en edades tempranas.

En cuanto a la duración de las intervenciones todas tienen una duración menor a un año excepto las realizadas por Fortea, Escandell, Castro \& Martos (2015) y Casenhiser, Shanker \& Stieben (2013). Otras son de tipo intensivo, en las que la intervención se aplica durante numerosas horas al día en pocos días, como en el trabajo de Houghton, Schuchard, Lewis \& Thompson (2013), con 40 horas de intervención en 5 días. Otra intervención con aplicación intensiva es la de Hill \& Flores (2014) pues su duración es de 21 días con 3 sesiones diarias y 5 días a la semana. En otros trabajos, las duraciones varían desde 8 semanas, en el caso de Barber, Saffo, Gilpin, Craft \& Goldstein (2016), 
en la intervención de Srinivasan, Eigsti, Gifford \& Bhat (2016) y en el estudio comparativo de Chang, Shire, Shih, Gelfand \& Kasari (2016), hasta 10 meses, en el caso de Karanth, Shaista \& Srikanth (2010). Otras intervenciones tienen una duración de 6 meses como el realizado por Landa, Holman, O'neill \& Stuart (2011) o Kasari, Kaiser, Goods, Nietfeld, Mathy, Landa, ... \& Almirall (2014). El resto de estudios tienen duraciones diferentes, en relación a los meses, semanas, días y sesiones diarias, y en algunos de ellos no se especifica la duración de la intervención. La duración del estudio se considera un elemento importante para comprobar la efectividad del tratamiento en los participantes. Además, en las intervenciones donde existe un seguimiento tras la intervención para evaluar su evolución, muestran que los efectos del tratamiento se mantienen en el tiempo.

A pesar de los efectos positivos obtenidos, el método que utilizan la mayoría de investigaciones incluidas en esta revisión se ve limitada, debido a: pocos estudios incluyen grupos de control para comparación del tratamiento, concretamente en 6 de los 24 estudios (Green, Charman, McConachie, Aldred, Slonims, Howlin, ... \& Barrett, 2010; Houghton, Schuchard, Lewis, \& Thompson, 2013; Casenhiser, Shanker, \& Stieben, 2013; Chang, Shire, Shih, Gelfand, \& Kasari, 2016; Srinivasa, Eigsti, Gifford \& Bhat, 2016; Rollins, 2018). En la mayoría falta seguimiento después de la aplicación de la intervención, ya que, solo existe seguimiento en los estudios de Kasari, Kaiser, Goods, Nietfeld, Mathy, Landa, ... \& Almirall (2014) y Chang, Shire, Shih, Gelfand, \& Kasari (2016). Destaca el tamaño de la muestra, siendo demasiado pequeñas y poco representativas, como en los casos de Ingersoll \& Wainer (2013) con solamente 8 participantes en el estudio, o el de Barber, Saffo, Gilpin, Craft \& Goldstein (2016) con 6 participantes de muestra o como en el caso del trabajo de Sutherland, O'Reilly, Lancioni \& Sigafoos (2012) con solamente 4 alumnos. Por otra parte, existen pocos estudios con aleatorización, solamente 3 de los 24 analizados: Casenhiser, Shanker, \& Stieben (2013), Rollins (2018) y Srinivasan, Eigsti, Gifford, \& Bhat (2016). Todas estas limitaciones son habituales en los estudios realizados con niños, en contexto natural y con necesidades educativas especiales.

En conclusión, para el diseño de intervenciones futuras es conveniente aumentar los esfuerzos para superar las limitaciones encontradas y tomar en consideración algunos aspectos clave que favorezcan el éxito de éstas. Esto significa, que se deben diseñar intervenciones que incluyan grupos de control, prolongarse en el tiempo, contar con seguimiento e incluir la participación de diferentes agentes educativos.

A continuación, se señalan los que se han considerado más pertinentes para la mejora de las intervenciones en este campo.

En primer lugar, contar en futuras intervenciones con posibilidades de interacción social de los niños con TEA y los de desarrollo normativo, por considerarse una estrategia comunicativa beneficiosa que permite al alumnado con TEA desenvolverse en el juego con sus iguales. Por otro lado, utilizar sistemas aumentativos y alternativos de comunicación (SAAC) como el lenguaje de signos, PECS o generadores de voz o de habla (SGD), pues se utilizan como alternativa al lenguaje para potenciar las peticiones en alumnado con TEA. En tercer lugar, contar con la participación de las familias y realizar intervención también desde el ámbito familiar con el fin de favorecer la interacción social general. En cuarto lugar, la utilización del juego también es una estrategia que ha aparecido en numerosas intervenciones, pues el juego favorece en el inicio de la interacción con otros alumnos, con el terapeuta e incluso con la familia. Otra técnica de comunicación a la que se debe prestar atención es la mirada y el contacto visual como medio de interacción, ya que, se trata de una habilidad comunicativa necesaria para mantener la atención durante las interacciones sociales y comprender 
los estados emocionales de los otros. Además, se debe trabajar la atención conjunta, pues permite compartir pensamientos comunes con otras personas sobre objetos, conceptos, etc.

Las implicaciones que de este estudio se derivan, se dirigen hacia la necesidad de trabajo conjunto desde escuela y familia, desde edades tempranas, en un contexto inclusivo como el actual. También destaca la necesidad de formación específica en TEA por parte del profesorado (Marín, Lizcano \& García, 2016b; Tárraga \& Sanz-Cervera, 2016) y del personal de pediatría, lo que favorecerá la pronta identificación del trastorno para realizar intervenciones ajustadas a las características de cada niño y niña, alumno y alumna para la mejora de competencias y habilidades necesarias para la vida, porque cada niño con TEA tiene unas necesidades concretas que deben ser abordadas con intervenciones personalizadas (Tárraga, Pastor, Tijeras, Sanz \& Fernández, 2018). No se debe olvidar que el fin último es el desarrollo armónico del individuo y la preparación para la vida, en un entorno que se ha de regir por el principio de inclusión, tal y como queda recogido en la legislación educativa actual (LOMCE, 2013).

\section{Referencias}

Adams, C., Lockton, E., Freed, J., Gaile, J., Earl, G., McBean, K., ... \& Law, J. (2012). The Social Communication Intervention Project: a randomized controlled trial of the effectiveness of speech and language therapy for school-age children who have pragmatic and social communication problems with or without autism spectrum disorder. International Journal of Language \& Communication Disorders, 47(3), 233-244.

Alcantud, F., \& Alonso, Y. (2018). Trastornos del Espectro Autista: Manual de Intervención Psicoeducativa. Universitat de València, Valencia.

American Psychiatric Association. (1980). Diagnóstic and Statistical Manual of Mental Disorders, 3rd Edition. Washington: American Psychiatric Association.

American Psychiatric Association. (2013). Diagnóstic and Statistical Manual of Mental Disorders. 5th Edition. Washington: American Psychiatric Association.

Baixauli-Fortea, I., Roselló-Miranda, B., Berenguer-Forner, C., Colomer-Diago, C. y Sevilla, MG. (2017). Intervenciones para promover la comunicación social en niños con trastornos del espectro autista. Revista de Neurología, 64(Supl 1), 39-44. Recuperado de http://go.uv.es/yi65EPx

Barber, AB., Saffo, RW., Gilpin, AT., Craft, LD., \& Goldstein, H. (2016). Peers as clinicians: Examining the impact of stay play talk on social communication in young preschoolers with autism. Journal of Communication Disorders, 59, 1-15.

Bondy, AS., \& Frost, LA. (1994). The picture exchange communication system. Focus on autistic behavior, 9(3), 1-19.

Bradshaw, J., Koegel, LK., \& Koegel, RL. (2017). Improving functional language and social motivation with a parentmediated intervention for toddlers with autism spectrum disorder. Journal of Autism and Developmental Disorders, 47(8), 2443-2458.

Brown, JA., \& Woods, JJ. (2016). Parent-implemented communication intervention: Sequential analysis of triadic relationships. Topics in Early Childhood Special Education, 36(2), 115-124.
Brown, JA., \& Woods, JJ. (2016). Parent-implemented communication intervention: Sequential analysis of triadic relationships. Topics in Early Childhood Special Education, 36(2), 115-124.

Casenhiser, DM., Shanker, SG., \& Stieben, J. (2013). Learning through interaction in children with autism: Preliminary data from asocial-communication-based intervention. Autism, 17(2), 220-241.

Chang, Y., Shire, SY., Shih, W., Gelfand, C., \& Kasari, C. (2016). Preschool deployment of evidence-based social communication intervention: JASPER in the classroom. Journal of Autism and Developmental Disorders, 46(6), 2211-2223.

Consejería de Educación (2007). Guía para la Atención Educativa del Alumnado con Trastorno Generalizado de Desarrollo (Autismo). Recuperado de: http://espectroautista.info/ficheros/publicaciones/atencioneducativa-del-alumnado-con-TGD.pdf

Dawson, G., Rogers, S., Munson, J., Smith, M., Winter, J., Greenson, J., ... \& Varley, J. (2010). Randomized, controlled trial of an intervention for toddlers with autism: The Early Start Denver Model. Pediatrics, 125(1), 17-23.

Dykstra, JR., Boyd, BA., Watson, LR., Crais, ER., \& Baranek, GT. (2012). The impact of the Advancing Social-communication And Play (ASAP) intervention on preschoolers with autism spectrum disorder. Autism, 16(1), 27-44.

Flippin, M., Reszka, S., \& Watson, LR. (2010). Effectiveness of the Picture Exchange Communication System (PECS) on communication and speech for children with autism spectrum disorders: A meta-analysis. American Journal of SpeechLanguage Pathology, 19(2), 178-195.

Fontao, MR. (2013). Caso clínico: intervención logopédica en un niño con dificultades en la interacción social, comunicación y lenguaje. Desenvolupament infantil i atenció precoç: revista de l'Associació catalana d'atenció precoç, 35, 1-9. 
Fortea, MS., Escandell, MO., Castro, JJ. y Martos, J. (2015). Desarrollo temprano del lenguaje en niños pequeños con trastorno del espectro autista mediante el uso de sistemas alternativos. Revista de neurología, 60(1), 31-50.

García, MP. (2002). Trastornos de la comunicación en autismo. Revista Galego Portuguesa de psicoloxía e educación, 8, 4094017.

Gattino, GS., Riesgo, RDS., Longo, D., Leite, JCL., \& Faccini, LS. (2011). Effects of relational music therapy on communication of children with autism: a randomized controlled study. Nordic Journal of Music Therapy, 20(2), 142-154.

Green, J., Charman, T., McConachie, H., Aldred, C., Slonims, V., Howlin, P., ..., \& Barrett, B. (2010). Parent-mediated communication-focused treatment in children with autism (PACT): a randomised controlled trial. The Lancet, 375, 21522160.

Haigh, SM., Walsh, JA., Mazefsky, CA., Minshew, NJ., \& Eack, SM. (2018). Processing speed is impaired in adults with autism spectrum disorder and relates to social communication abilities. Journal of Autism and Developmental Disorders, 48(8), 2653-2662.

Hill, DA., \& Flores, MM. (2014). Comparing the picture exchange communication system and the $\mathrm{IPad}^{\mathrm{TM}}$ for communication of students with autism spectrum disorder and developmental delay. TechTrends: Linking Research and Practice to Improve Learning, 58(3), 45-53.

Houghton, K., Schuchard, J., Lewis, C. y Thompson, CK. (2013). Promover la comunicación social iniciada por el niño en niños con autismo: Efectos de la intervención con el the son-rise program $®$. Journal of Communication Disorders, 46, 495-506.

Ingersoll, B., \& Wainer, A. (2013). Initial efficacy of Project ImPACT: A parent-mediated social communication intervention for young children with ASD. Journal of Autism and Developmental Disorders, 43(12), 2943-2952.

Karanth, P., Shaista, S., \& Srikanth, N. (2010). Efficacy of Communication DEALL-An indigenous early intervention program for children with autism spectrum disorders. The Indian Journal of Pediatrics, 77(9), 957-962.

Kasari, C., Kaiser, A., Goods, K., Nietfeld, J., Mathy, P., Landa, R., ..., \& Almirall, D. (2014). Communication interventions for minimally verbal children with autism: A sequential multiple assignment randomized trial. Journal of the American Academy of Child \& Adolescent Psychiatry, 53(6), 635-646.

Krstovska, I., \& Jones, EA. (2016). Social-communication intervention for toddlers with autism spectrum disorder: Eye gaze in the context of requesting and joint attention. Journal of Developmental and Physical Disabilities, 28(2), 289-316.

Landa, RJ., Holman, KC., O'neill, AH., \& Stuart, EA. (2011). Intervention targeting development of socially synchronous engagement in toddlers with autism spectrum disorder: a randomized controlled trial. Journal of Child Psychology and Psychiatry, 52(1), 13-21.

Ley Orgánica de Mejora de la Calidad Educativa (LOMCE, 12/2013).

Marín, D., Lizcano, L. y García, C. (2016a). Software educativo para el desarrollo de la lectoescritura en el Aula de Comunicación y Lenguaje. DIM: Didáctica, Innovación y Multimedia, 34, 1-10.
Marín, D., Lizcano, L. y García, C. (2016b). Las aulas de comunicación y lenguaje: Características y formación del profesorado. Quaderns digitals: Revista de Nuevas Tecnologías y Sociedad, 83, 55-65.

Martos Pérez, J. y Paula Pérez, I. (2011). Una aproximación a las funciones ejecutivas en el trastorno del espectro autista. Revista de Neurología, 52(1), 147-53.

Monfort, I. (2009). Comunicación y lenguaje: bidireccionalidad en la intervención en niños con trastorno de espectro autista. Revista de Neurología, 48(2), 53-56.

Muzammal, MS., \& Jones, EA. (2017). Social-communication intervention for toddlers with autism spectrum disorder: Effects on initiating joint attention and interactions with mother. Journal of Developmental and Physical Disabilities, 29(2), 203-221.

Poon, KK., \& Sidhu, DJK. (2017). Adults with autism spectrum disorders: A review of outcomes, social attainment, and interventions. Current Opinion in Psychiatry, 30(2), 77-84.

Radley, KC., Jenson, WR., Clark, E., Hood, JA., \& Nicholas, P. (2014). Using a multimedia social skills intervention to increase social engagement of young children with autism spectrum disorder. Intervention in School and Clinic, 50(1), 22-28.

Ramdoss, S., Lang, R., Mulloy, A., Franco, J., O'Reilly, M., Didden, R., \& Lancioni, G. (2011). Use of computer-based interventions to teach communication skills to children with autism spectrum disorders: A systematic review. Journal of Behavioral Education, 20(1), 55-76.

Reetzke, R., Zou, X., Sheng, L., \& Katsos, N. (2015). Communicative development in bilingually exposed Chinese children with autism spectrum disorders. Journal of Speech, Language, and Hearing Research, 58(3), 813-825.

Reichow, B., \& Volkmar, FR. (2010). Social skills interventions for individuals with autism: Evaluation for evidence-based practices within a best evidence synthesis framework. Journal of autism and developmental disorders, 40(2), 149-166.

Rivière, Á. (1999). Lenguaje y autismo. En D. Valdez (coord.), Autismo, enfoques actuales para padres y profesionales de la salud y la educación (pp. 15-42). Buenos Aires: Fundec.

Rollins, P. R. (2018). Setting the stage: Creating a social pragmatic environment for toddlers with ASD and their caregivers. Revista De Logopedia, Foniatría y Audiología, 38(1), 14-23. DOI: http://dx.doi.org/10.1016/j.rlfa.2017.11.001

Romero, NL. (2017). A Pilot Study Examining a Computer-Based Intervention to Improve Recognition and Understanding of Emotions in Young Children with Communication and Social Deficits. Research in developmental disabilities, 65, 35-45.

Rose, V., Trembath, D., Keen, D., \& Paynter, J. (2016). The proportion of minimally verbal children with autism spectrum disorder in a community-based early intervention programme. Journal of Intellectual Disability Research, 60(5), 464-477.

Sanz-Cervera, P., Fernández-Andrés, MI., Pastor-Cerezuela, G., \& Tárraga-Mínguez, R. (2018). Efectividad de las intervenciones basadas en metodología TEACCH en el trastorno del espectro autista: un estudio de revisión. Papeles del psicólogo, 39(1), 40-50. 
Schaeffer, B., Musil, A., \& Kollinzas, G. (1980). Total Communication: A signed speech program for non-verbal children. Research Press.

Siller, M., Hutman, T., \& Sigman, M. (2013). A parent-mediated intervention to increase responsive parental behaviors and child communication in children with ASD: A randomized clinical trial. Journal of autism and developmental disorders, 43(3), 540-555.

Sowden, H., Perkins, M., \& Clegg, J. (2011). Context and communication strategies in naturalistic behavioural intervention: A framework for understanding how practitioners facilitate communication in children with ASD. Child Language Teaching and Therapy, 27(1), 21-38.

Srinivasan, SM., Eigsti, I., Gifford, T., \& Bhat, AN. (2016). The effects of embodied rhythm and robotic interventions on the spontaneous and responsive verbal communication skills of children with autism spectrum disorder (ASD): A further outcome of a pilot randomized controlled trial. Research in Autism Spectrum Disorders, 27, 73-87.

Tárraga, R. y Sanz-Cervera, P. (2016). La formación del profesorado ante la educación de los niños con necesidades educativas especiales. En Suárez, C.; Marín, D. y Palomares, D. (coords.) Retos de la educación en tiempos de cambio (253276). Valencia, España: Tirant Lo Blanch.

Tárraga, R., Pastor, G., Tijeras, A., Sanz, P. y Fernández, I. (2018). Alumnado con trastorno del espectro autista. En Marín, D. y
Fajardo, I. (cords.). (2018). Intervención en Alumnos con Necesidades Específicas de Apoyo Educativo (188-209). Valencia, España: Tirant Lo Blanch.

Tordera, JC. (2007). Trastorno de espectro autista: delimitación lingüística. Estudios de Lingüística de la Universidad de Alicante (ELUA), 21, 301-314

Van der Meer, LA., \& Rispoli, M. (2010). Communication interventions involving speech-generating devices for children with autism: A review of the literature. Developmental Neurorehabilitation, 13(4), 294-306.

Van der Paelt, S., Warreyn, P., \& Roeyers, H. (2014). Effect of community interventions on social-communicative abilities of preschoolers with autism spectrum disorder. Developmental Neurorehabilitation, 19(3), 162-174.

Van, d. M., Sutherland, D., O'Reilly, MF., Lancioni, GE., \& Sigafoos, J. (2012). A further comparison of manual signing, picture exchange, and speech-generating devices as communication modes for children with autism spectrum disorders. Research in Autism Spectrum Disorders, 6(4), 1247-1257.

Yoder, PJ., \& Lieberman, RG. (2010). Brief report: Randomized test of the efficacy of picture exchange communication system on highly generalized picture exchanges in children with ASD. Journal of Autism and Developmental Disorders, 40(5), 629-632. 